\title{
Evaluating the chemical stability in drinking water distribution system by corrosivity and precipitation potential
}

\author{
Baoyou Shi, Yunjie Wan, Ying Yu, Junnong Gu and Gangliang Wang
}

\begin{abstract}
$\overline{\text { ABSTRACT }}$
Calcium carbonate equilibrium-based indices, such as calcium carbonate precipitation potential (CCPP), have long been used as indicators of water chemical stability. The Larson ratio (LR) is a non- $\mathrm{CaCO}_{3}$ based index for measuring water corrosivity against iron pipes, but the involved mechanisms and application of LR are not completely understood. To understand the applicability of the two indices on iron corrosion product release in drinking water distribution systems (DWDS), unlined cast iron pipes were harvested from a real DWDS to establish pilot-scale experimental systems, and different chemicals were used to adjust LR and CCPP values of the pipe feed waters. Results showed that iron release increased with LR increase, but at the same LR, chloride adjustment could lead to more iron release than sulphate. When using different chemicals to adjust CCPP to the same level, the iron release could be significantly different, with $\mathrm{NaHCO}_{3}$ addition causing the lowest release. Increasing the alkalinity by $\mathrm{Ca}(\mathrm{OH})_{2}$ and $\mathrm{CO}_{2}$, which could be the most efficient and economic method for inhibiting iron release in DWDS, increased the CCPP and reduced the LR simultaneously. The crystalline composition characteristics of iron pipe corrosion scales also played a critical role in the iron release behavior.

Key words | calcium carbonate precipitation potential, chemical stability, drinking water distribution system, iron release, Larson ratio, red water
\end{abstract}

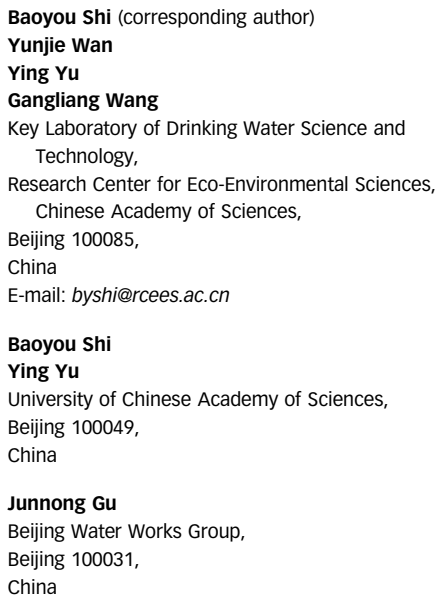

\section{INTRODUCTION}

It is known that treated finished water satisfying regulations might not guarantee the same water quality at consumer taps. Water quality changes in drinking water distributions systems (DWDS) can result from complicated physical, chemical, and biological processes. Discolored water is one of the most common water quality deterioration scenarios in DWDS, and it can damage the service image of water utilities and decrease the confidence of customers in regard to water quality (Vreeburg \& Boxall 2007).

There are different types of discolored water that involve complicated mechanisms. Residual dissolved manganese in treated water can be oxidized into insoluble particles, which tend to attach and deposit on pipe walls, and re-suspension of such particulate manganese is a typical kind of discolored water in some places (Sly et al. 1990). However, the corrosion product release in metallic pipes is the most common type of red water. Unlined cast iron pipe is still widely existed in current distribution systems all over the world, particularly in some old and large cities. The inner walls of this kind of pipe are usually covered by iron corrosion products that form scales. Iron corrosion scales with different morphologies and structures have been reported by many researchers, and the structural characteristics of corrosion scales greatly affect the iron release behavior (Sarin et al. 200I; Tang et al. 2006; Gerke et al. 2008; Yang et al. 20I2). Under normal conditions, iron 
release in these pipes is relatively weak and no obvious color appears at customers' taps. However, when the water experiences long stagnation or a sudden increase of flow rate happens, heavily colored water or red water can be formed. Usually this kind of colored water disappears rapidly after flushing for a short period. Another kind of red water, which may last for months, can happen when the water chemical characteristics entering the DWDS change significantly. Many events have confirmed that a source water switch can trigger such red water issues. The city of Tucson, Arizona, USA suffered from a serious red water crisis in 1992 when the source water was switched from local groundwater to Colorado River water. The city of Beijing, China also encountered a relatively long red water period in some communities when introducing reservoir water from a neighbouring province to replace local groundwater. A recent water quality crisis related to a source water switch was reported in Flint, Michigan, USA. In this case, in addition to red water, concomitant lead release from old lead pipes drew attention to the safety of the drinking water (Rosario-Ortiz et al. 20I6). Unfortunately, there is still no clear understanding of the mechanisms by which iron corrosion products associated red water occur, and no reliable way to predict or control such events when applying a new water source or changing treatment trains.

The Langelier Saturation Index (LSI) has been used to evaluate the chemical stability of water in a distribution system by water utilities since the 1930s. The basic theory of this method is that a calcium carbonate film on the pipe surface inhibits pipe corrosion and corrosion product release. The calcium carbonate precipitation potential (CCPP) was developed to quantitatively predict the theoretical amount of calcium carbonate formed under certain water quality conditions. Some other empirical indices based on calcium carbonate precipitation have also been proposed to evaluate the chemical stability of treated water, such as the Aggression index, Ryznar index, etc. However, the effectiveness of this category of index for predicting iron corrosion and release could be low due to the complexity of involved mechanisms (McNeill \& Edwards 200I; Sarin et al. 2004; Imran et al. 2005a, 2015b). In fact, even with high positive LSI or CCPP values, calcium carbonate film is rarely observed on pipe walls. On the other hand, severe red water can occur when conducting a source water switch even when the new source water has high positive LSI and CCPP values.

The Larson ratio (LR) was put forward by Larson \& Skold (1958) to evaluate water corrosivity to iron pipes. In this ratio, sulphate and chloride are considered to be corrosive factors and bicarbonate an inhibitive factor. Although this index was proposed more than a half century ago, the mechanisms associated with it have not been fully understood, particularly when it is used for old, corroded iron pipes. Recent research has found that elevated sulphate or chloride can increase corrosion product release in iron distribution pipes, while high bicarbonate concentration can significantly decrease iron corrosion product release (Lytle et al. 2005; Yang et al. 2014). However, no well recognized quantitative relationship between iron release and LR has been established. A modified LR index was therefore put forward by Imran et al. (2005a, 2005b).

In the present work, a relatively large distribution system simulation set-up was utilized to investigate the effect of feed water quality changes on iron corrosion product release. Test iron pipes with different water source histories were excavated from real DWDS of Beijing, China. The focus of this study was to elucidate the roles of some main water quality parameters related to the aforementioned indices in iron corrosion product release, and thus to reveal the applicability of these indices for evaluating water chemical stability. CCPP and LR were selected as two typical indices for evaluating iron release behaviors. The findings of this work could also provide some understanding of red water mechanisms and help to avoid red water when switching source water or changing water treatment processes.

\section{MATERIAL AND METHODS}

\section{Test pipes}

Two unlined cast iron pipes (denoted as Pipe-Q and Pipe-S) were harvested from two different locations of the DWDS in Beijing, China, and the water of these two locations was from different treatment plants. The length of each pipe was 30 meters with a nominal diameter of $100 \mathrm{~mm}$ 
(DN100). Pipes of this size are usually located at the end of the distribution system, where water quality problems more frequently occur. The pipe ages were around 20 years. To avoid disturbing the corrosion scales, the pipes were handled with great care during all operations from excavation to instalment onto the experimental scaffold. To keep the pipes fresh, they were cut out just after suspending the water supply and were transported to the experimental field within two days, and the two ends of each pipe were covered with plastic film to keep them wet inside. The experimental field was near Danjiangkou Reservoir (within the Yangtze River watershed), which is the source water of the 'South to North Water Diversion (the middle route)' project in China. This research work was conducted before the Danjiangkou Reservoir water came into Beijing and it is a part of a series of studies aimed to investigate the effects of water diversion on water quality in the DWDS of Beijing.

\section{Experiment set-up}

The experimental set-up is shown in Figure 1. Two pipe loops could run simultaneously. Each pipe loop with 6 equal length pipe sections were arranged in parallel and connected by plastic elbows. The pipe loop could be operated in two modes: one was where water was fed and driven by a centrifugal pump and circulated in the loop to mimic a relatively high flow rate in the DWDS $\left(15 \mathrm{~m}^{3} / \mathrm{h}\right)$. For this mode, the hydraulic retention time (HRT) was equal to the pump running time. The other mode was

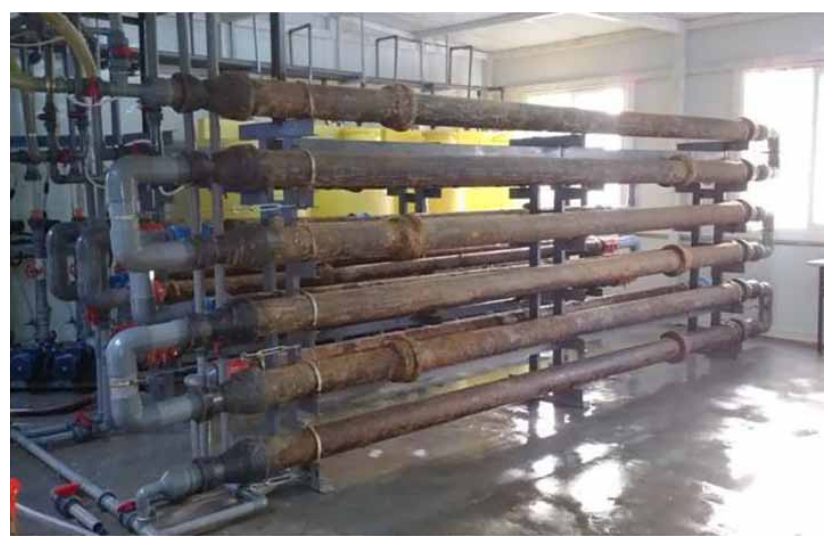

Figure 1 | The experimental set-up. where the water was fed and driven by a metering pump without circulation. The flow rate of this mode was quite low to simulate the night time flow conditions. The HRT for this mode could be changed by adjusting the metering pump. In this work, except for the initial equilibration period, an HRT of 24 hours using the metering pump was the normal operating condition. After each run, flushing at high flow rate $\left(15 \mathrm{~m}^{3} / \mathrm{h}\right)$ using the centrifugal pump was carried out to avoid accumulation of loose deposits.

\section{Experimental operation}

The experimental field was about 1,200 km away from Beijing. At the beginning of the experiment, local treated surface water was used to establish a new equilibrium for the pipes, and centrifugal pumps and metering pumps were run alternatively to simulate high and low flow patterns that occur over the course of a day. After reaching equilibrium, the feed water LR and CCPP were adjusted by adding different chemicals in predetermined amounts to investigate the iron release behavior of the two pipes. Chemicals used were all reagent grade.

\section{Water quality analysis}

Quality parameters of water entering and leaving the pipe test loops were analysed on a daily basis. The $\mathrm{pH}$ and dissolved oxygen were measured using a portable HQ40d Multi-parameter (Hach, USA). Turbidity was measured using a Hach 2100P Turbidimeter. Chlorine residual, total iron, and sulphate and chloride were measured using a Hach DR2800 Spectrophotometer. Measurement protocols provided by instrument manufacture were followed. Calcium and alkalinity were measured using standard titration methods.

\section{Corrosion scale characterization}

Corrosion scale samples were vacuum freeze-dried and pulverized in an anaerobic glove box after collection, then X-ray diffraction (XRD, D/max-rA, Rigaku Co., USA) patterns were obtained to analyse the crystalline composition of the corrosion scale samples (Yang et al. 2012). 


\section{RESULTS AND DISCUSSION}

\section{Iron release behavior of the test pipes after initial source water switch}

The iron release change with time after switching to new source water in the experimental field is shown in Figure 2. In this work, the iron release is expressed as the mass of iron released into the water per square meter of pipe wall area per hour, in units of $\mathrm{mg} /\left(\mathrm{m}^{2} \cdot \mathrm{h}\right)$, which can be calculated from the measured iron concentration increase, the pipe geometrical dimensions and the HRT. The iron release decreased gradually with time from day 1 to day 25. After 25 days, the iron release was maintained at a relatively stable level, which meant re-equilibration was reached. The iron release of Pipe-Q was significantly higher than that of Pipe-S during this period. To understand the iron release differences of the two pipes, the general water quality characteristics corresponding to the two pipes transported before and after the source water switch are

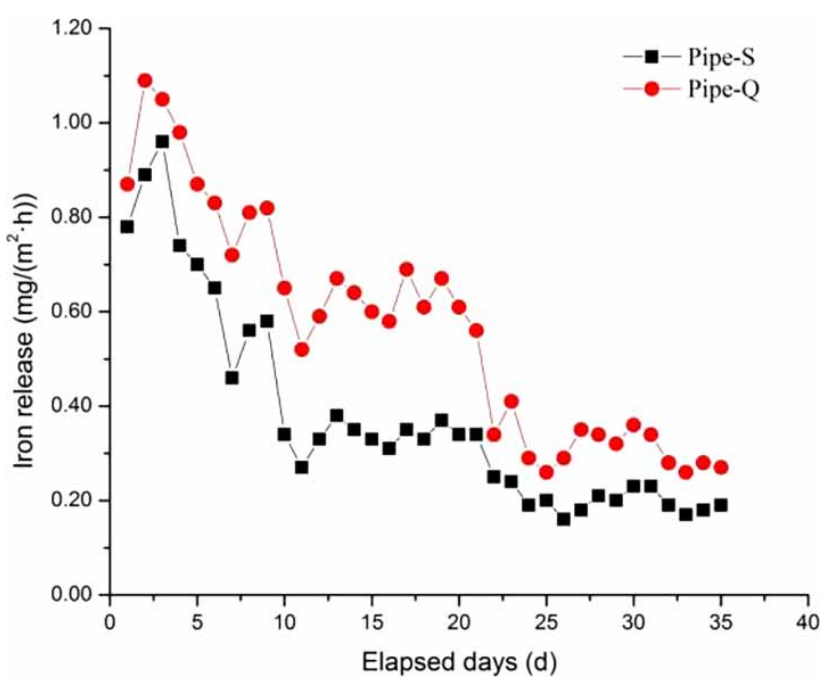

Figure 2 | Iron releases of Pipe-Q and Pipe-S with time after source water switch. provided in Table 1. The original waters of Pipe-Q and Pipe-S before transport are denoted as Water-Q and Water-S, respectively, and the water used in the experimental field is denoted as Water-F.

The $\mathrm{pH}$ of Water-F was a little higher than those of the two original waters. Water-S had the highest alkalinity and calcium hardness, and thus its CCPP was also the highest. The sulphate concentration of Water-S was the highest, and it had the highest LR value. The sulphate and LR of Water-Q and Water-F were similar. Previous research has found that corrosion scales formed under higher sulphate or LR can become more stable than those formed under lower sulphate and LR (Yang et al. 20I4). Corrosion scales formed under higher sulphate or LR water usually exhibit heavy tubercle morphology, and the dense top layer of the tubercle can effectively inhibit iron release. However, corrosion scales formed under low sulphate or LR water are rather thinner and less dense. When switched to more corrosive water, higher iron release can occur (Yang et al. 2012). Thus, it might be that the lower iron release of Pipe-S after the source water switch was due to its more stable corrosion scales formed under higher sulphate concentrations. As to the role of CCPP, further studies are needed.

\section{Effect of LR adjustment by sulphate and chloride on iron release}

LR can be calculated by the sum of sulphate and chloride equivalents divided by the bicarbonate equivalent. In order to evaluate the reliability of LR for predicting iron release, the LR of experimental water (Water-F) was elevated to 3.0 by adding either sodium sulphate or sodium chloride. The iron release of Pipe-Q and Pipe-S before and after LR modification is presented in Figure 3. Compared with the non-chemical adjusted water, the LR adjustment resulted in increased iron release, which is in agreement with previous research (Lytle et al. 2005; Yang et al. 2014).

Table 1 | Water quality parameters of original water of test pipes and the new water

\begin{tabular}{|c|c|c|c|c|c|c|c|c|}
\hline & pH & Alkalinity $\left(\mathrm{mg} / \mathrm{L}\right.$ as $\left.\mathrm{CaCO}_{3}\right)$ & Calcium (mg/L as $\left.\mathrm{CaCO}_{3}\right)$ & $\mathrm{SO}_{4}^{2-}(\mathrm{mg} / \mathrm{L})$ & $\mathbf{C l}^{-}(\mathbf{m g} / \mathbf{L})$ & Turbidity (NTU) & LR & $\operatorname{CCPP}\left(\mathrm{mg} / \mathrm{L}\right.$ as $\left.\mathrm{CaCO}_{3}\right)$ \\
\hline Water-Q & 7.86 & 141 & 146 & 26 & 13 & 0.3 & 0.32 & 6.83 \\
\hline Water-S & 7.81 & 181 & 201 & 93 & 19 & 0.2 & 0.69 & 20.22 \\
\hline Water-F & 8.20 & 110 & 109 & 26 & 5 & 0.5 & 0.31 & 5.79 \\
\hline
\end{tabular}




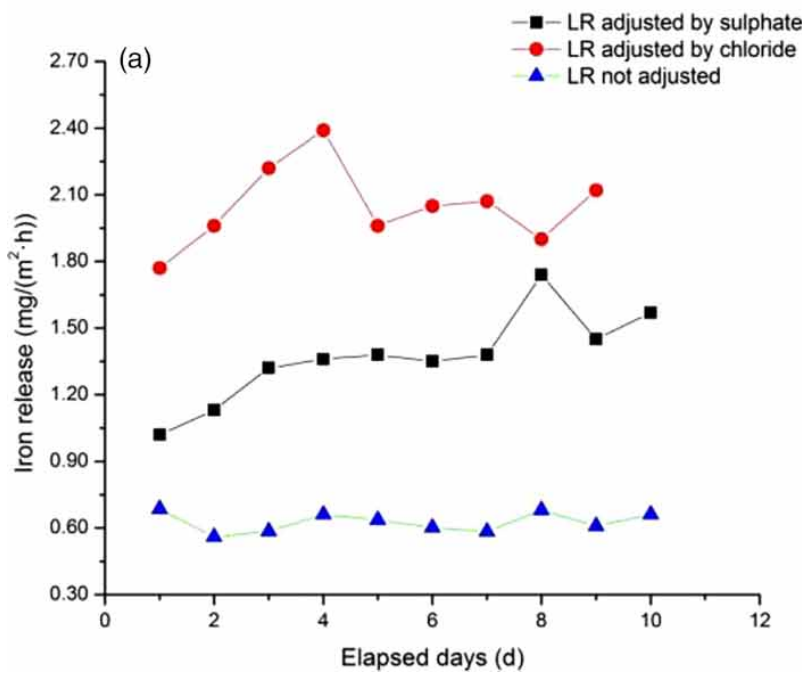

Figure 3 | Iron releases of Pipe-Q (a) and Pipe-S (b) before and after LR adjustment.

Furthermore, it was obvious that chloride resulted in significantly higher iron release than sulphate even though the LR was raised to the same level by the two ions. This indicated that equivalent amounts of sulphate and chloride might not play equivalent roles in terms of iron release.

For the two aforementioned red water cases (Tucson and Beijing), some common factors were as follows: the source water switch was from local groundwater to foreign surface water, and the new source water had much higher sulphate concentration than the original water. Meanwhile, the LR values of the new source waters were elevated by multiple amounts compared with the original waters. Both the experimental research and real source water switch cases confirm that increased LR values can trigger increased iron release or even red water. However, the possibly different weight coefficients of sulphate and chloride should be taken into consideration when using LR to evaluate water corrosivity (chemical stability) in terms of iron release.

\section{Effect of CCPP modification by different chemicals on iron release}

The water quality parameters used to caculate CCPP include $\mathrm{pH}$, alkalintiy, and calcium concentration. In this work, CCPP values were obtained by a Tetra Tech Rtw Model (AWWA, USA). $\mathrm{NaOH}, \mathrm{NaHCO}_{3}, \mathrm{CaCl}_{2}$, and $\mathrm{Ca}(\mathrm{OH})_{2}$ were used respectively to increase the CCPP of Water-F to a similar level of around $17 \mathrm{mg} / \mathrm{L}$. The iron release of the

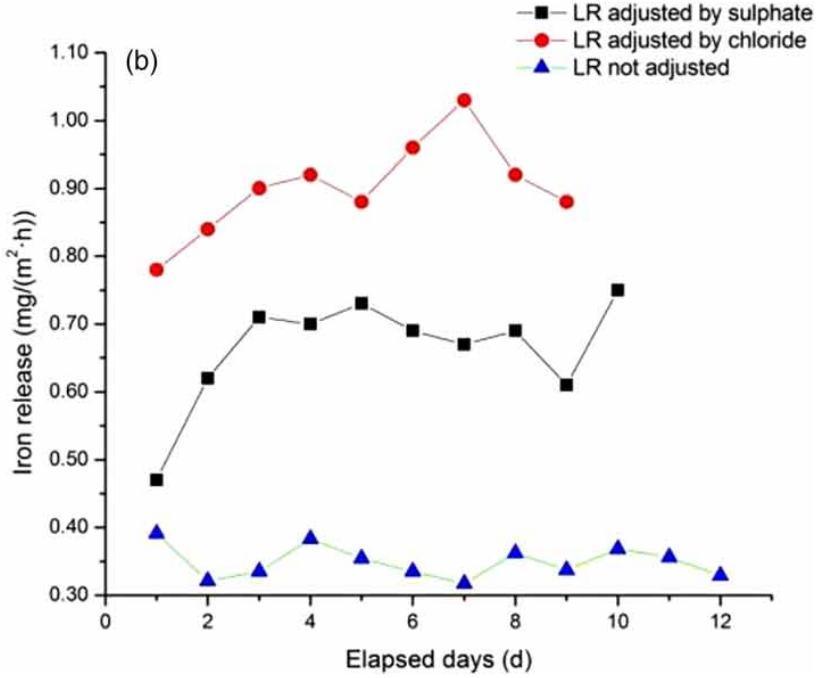

two pipes after CCPP modification is shown in Figure 4. It was observed that although the feed waters had similar CCPP, their iron release was at different levels. $\mathrm{NaHCO}_{3}$ addition achieved the lowest iron release, while the $\mathrm{CaCl}_{2}$ addition caused the highest iron release. For Pipe-Q, the iron release with $\mathrm{NaOH}$ was lower than that with $\mathrm{Ca}(\mathrm{OH})_{2}$, but for pipe-S, the iron release with $\mathrm{Ca}(\mathrm{OH})_{2}$ was a little lower. These results imply that CCPP might not be a reliable index to evaluate the chemical stability of water in terms of iron release. When $\mathrm{CaCl}_{2}$ is dosed, although the calcium elevation can increase the CСPP, the simutaneous introduction of chloride might accelarate iron release instead.

Alkalinity (equivent to bicarbonate in natural waters) is the only common parameter for LR and CCPP calculation. Increase of alkalinity can reduce the LR and increase the CCPP at the same time, both of which are beneficial to the inhibition of iron release. Therefore, increasing the water alkalinity should be a more efficient method to impove the chemical stabiltiy of water in distribution systems.

\section{Effect of alkalinity adjustment by $\mathrm{Ca}(\mathrm{OH})_{2}$ and $\mathrm{CO}_{2}$}

Although $\mathrm{NaHCO}_{3}$ addition can easily increase water alkalinity, the usage of such chemicals in large-scale water treatment plants is not cost-effective. Since the reaction between $\mathrm{Ca}(\mathrm{OH})_{2}$ and $\mathrm{CO}_{2}$ in water can form soluble $\mathrm{Ca}\left(\mathrm{HCO}_{3}\right)_{2}$, which is the main alkalinity constituent in 

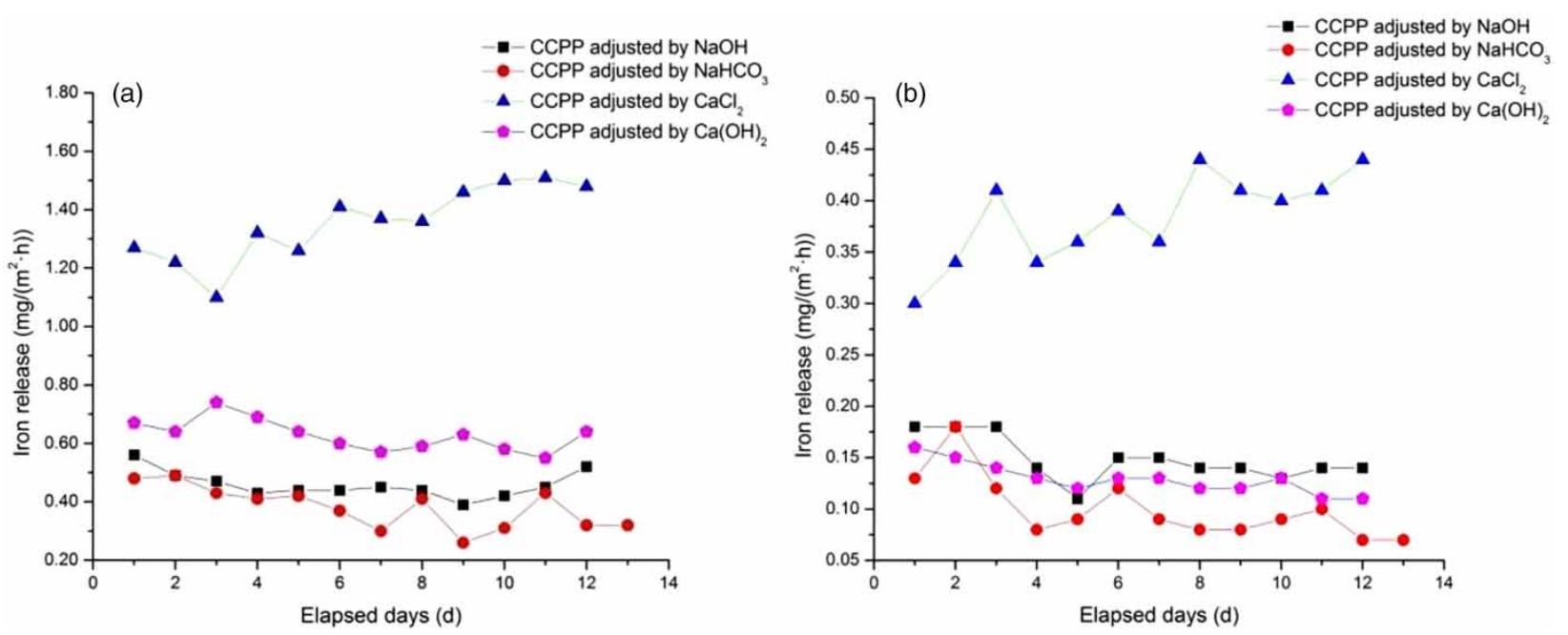

Figure 4 | Iron releases of Pipe-Q (a) and Pipe-S (b) before and after CCPP adjustment.

natural water, we investigated the effect of adding $\mathrm{Ca}(\mathrm{OH})_{2}$ and $\mathrm{CO}_{2}$ on iron release inhibition (Figure 5).

When different amounts of $\mathrm{Ca}(\mathrm{OH})_{2}$ were added into feed water, sufficient amounts of $\mathrm{CO}_{2}$ were introduced to allow $\mathrm{Ca}\left(\mathrm{HCO}_{3}\right)_{2}$ formation. Figure 5 shows that with the increase of $\mathrm{Ca}(\mathrm{OH})_{2}$ dosage, more $\mathrm{Ca}\left(\mathrm{HCO}_{3}\right)_{2}$ was transformed and consequently less iron was released. Thus, the combined application of $\mathrm{Ca}(\mathrm{OH})_{2}$ and $\mathrm{CO}_{2}$ could be a practical method for improving the chemical stability of drinking water in distribution systems, which can reduce LR and increase CCPP simultaneously.

\section{General discussion}

When the same water was fed into different pipes under the same operating conditions, different iron release responses resulted from the different corrosion scale characteristics. The crystalline composition of corrosion scales for Pipe-Q and Pipe-S are listed in Table 2 (the initial state before switching to Water-F). Magnetite $\left(\mathrm{Fe}_{3} \mathrm{O}_{4}\right)$ is considered to play an important role in the formation of dense and stable corrosion scales (Sarin et al. 2004; Yang et al. 2012). Both Pipe-Q and Pipe-S contained a significant amount of
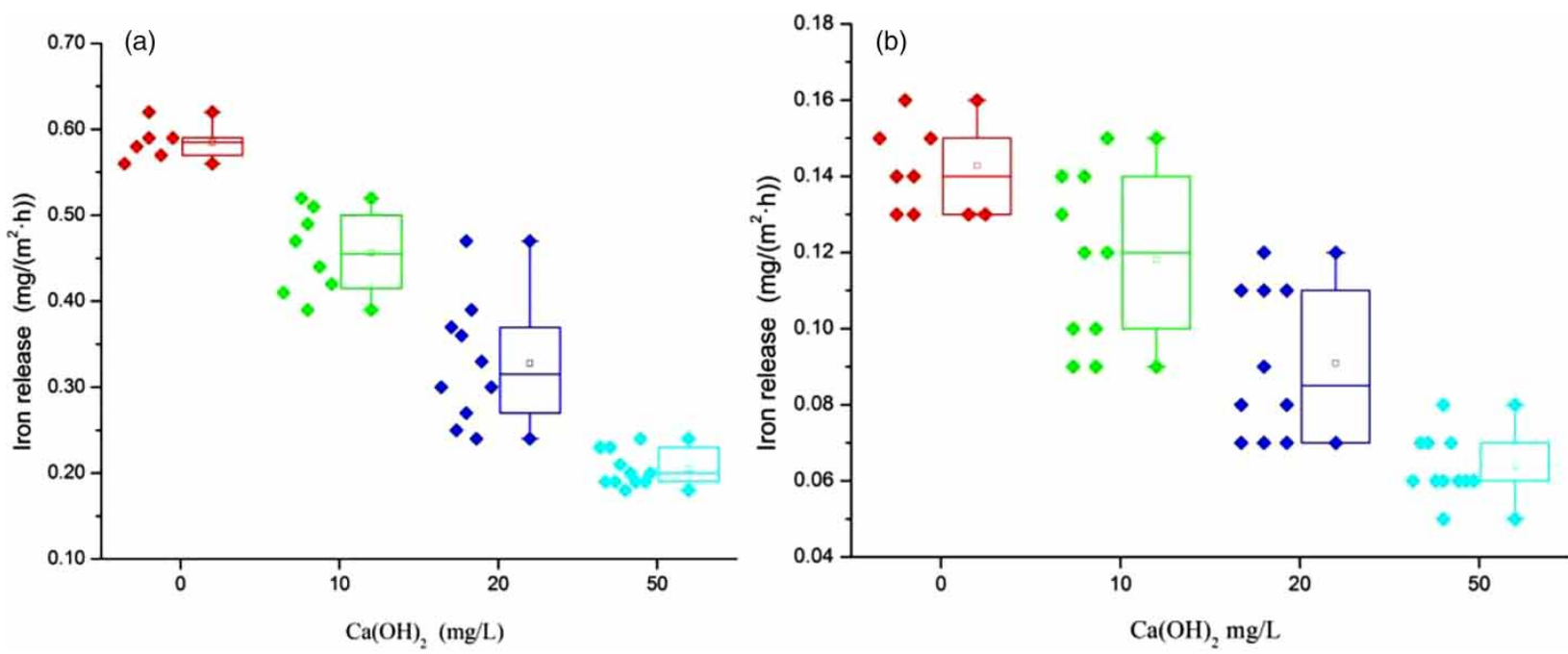

Figure 5 | Iron release of Pipe-Q (a) and Pipe-S (b) with $\mathrm{Ca}(\mathrm{OH})_{2}$ and $\mathrm{CO}_{2}$ addition. 
Table 2 | Crystalline matter composition of corrosion scales for Pipe-Q and Pipe-S (\%).

\begin{tabular}{|c|c|c|c|c|c|c|c|c|}
\hline & Magnetite & Lepidocrocite & Goethite & Siderite & Akaganeite & Calcite & Zeolite & Rutile \\
\hline Pipe-Q & 25 & 3 & 21 & 3 & 30 & 0 & 0 & 0 \\
\hline Pipe-S & 17 & 8 & 28 & 5 & 12 & 18 & 21 & 10 \\
\hline
\end{tabular}

magnetite, $25 \%$ and $17 \%$, respectively. On the other hand, the content of akaganeite $(\beta$-FeOOH) for Pipe-Q $(30 \%)$ was much higher than that of Pipe-S (12\%). Akaganeite is a chemically unstable constituent and is unfavourable for dense corrosion scale formation. The higher akaganeite content of Pipe-Q might be responsible for its higher iron release when switching to new source water. During the LR and CCPP adjustment experiments, the iron release corresponding to Pipe-Q was always higher than that of Pipe-S. We also found that calcite $\left(\mathrm{CaCO}_{3}\right)$ was in the corrosion scale of Pipe-S but not in the scale of Pipe-Q. This could be explained by the much higher calcium content and CCPP of Water-S than of Water-Q.

In order to understand the relationship between calcium carbonate precipitation and iron release, we calculated the correlation between $\Delta \mathrm{Ca}$ and $\Delta \mathrm{Fe}$ (the measured calcium and iron concentration differences between effluent and influent water, respectively). Linear regression coefficients of 0.78 and 0.88 for Pipe-Q and Pipe-S were obtained, respectively. The higher the iron release, the more calcium was precipitated. This implies that calcium carbonate precipitation might be enhanced by the iron corrosion and release process. According to galvanic cell corrosion principles, local higher $\mathrm{pH}$ on the pipe surface could form, when elemental iron is oxidized to ferrous iron.

Precipitation of calcium carbonate may help to form denser corrosion scales, but the relative importance of LR and CCPP should be considered for practical evaluation of chemical stability.

\section{CONCLUSIONS}

The effect of water chemical characteristics on the corrosion of iron pipes and corrosion product release is important for evaluating the chemical stability of drinking water in distribution systems. Calcium carbonate equilibrium-based indices, such as LSI and CCPP, have been widely used as guidelines for finished water adjustment. However, these kinds of indices may be invalid for iron release control, especially when switching source water or changing water treatment.

Iron release increased significantly with the increase of LR, but chloride resulted in more iron release than an equivalent amount of sulphate. When using different chemicals to increase CCPP to similar levels, iron release can be greatly different. Alkalinity is a critical parameter for both CCPP and LR, and thus an increase of alkalinity might be an efficient means of inhibiting iron pipe corrosion and corrosion product release. The addition of $\mathrm{Ca}(\mathrm{OH})_{2}$ together with $\mathrm{CO}_{2}$ aeration could increase alkalinity and calcium simultaneously without introducing corrosive factors. This could be a practical measure to avoid red water occurrence in the case of a source water switch or when water treatment changes cause low alkalinity and high LR water.

\section{ACKNOWLEDGEMENTS}

This work was supported by the National Natural Science Foundation of China (51378493, 51678558) and National Key Research \&Development Program of China (2016YFC0400803).

\section{REFERENCES}

Gerke, T. L., Maynard, J. B., Schock, M. R. \& Lytle, D. L. 2008 Physiochemical characterization of five iron tubercles from a single drinking water distribution system: possible new insights on their formation and growth. Corrosion Science 50 (7), 2030-2039.

Imran, S. A., Dietz, J. D., Mutoti, G., Taylor, J. S. \& Randall, A. A. 2005a Modified Larson's ratio incorporating temperature, water age, and electroneutrality effects on red water release. Journal of Environmental Engineering 11, 1514-1520. 
Imran, S. A., Dietz, J. D., Mutoti, G., Taylor, J. S., Randall, A. A. \& Cooper, C. D. 2005b Red water release in drinking water distribution systems. Journal American Water Works Association 97 (9), 93-100.

Larson, T. E. \& Skold, R. V. 1958 Laboratory studies relating mineral quality of water to corrosion of steel and cast iron. Journal American Water Works Association 14 (6), 285-288.

Lytle, D. A., Sarin, P. \& Snoeyink, V. L. 2005 The effect of chloride and orthophosphate on the release of iron from a cast iron pipe section. Journal of Water Supply Research and Technology-Aqua 54 (5), 267-281.

McNeill, L. S. \& Edwards, M. 200I Iron pipe corrosion in distribution systems. Journal American Water Works Association 93 (7), 88-100.

Rosario-Ortiz, F., Rose, J., Speight, V., von Gunten, U. \& Schnoor, J. 2016 How do you like your tap water? Science 351 (6276), 912-914.

Sarin, P., Snoeyink, V. L., Bebee, J., Kriven, W. M. \& Clement, J. A. 200I Physico-chemical characteristics of corrosion scales in old iron pipes. Water Research 35 (12), 2961-2969.

Sarin, P., Snoeyink, V. L., Lytle, D. A. \& Kriven, W. M. 2004 Iron corrosion scales: model for scale growth, iron release, and colored water formation. Journal of Environmental Engineering 130 (4), 364-373.

Sly, L. I., Hodgkinson, M. C. \& Arunpairojana, V. rg9o Deposition of manganese in a drinking-water distribution-system. Applied and Environmental Microbiology 56 (3), 628-639.

Tang, Z. J., Hong, S. K., Xiao, W. Z. \& Taylor, J. S. 2006 Characteristics of iron corrosion scales established under blending of ground, surface, and saline waters and their impacts on iron release in the pipe distribution system. Corrosion Science 48 (2), 322-342.

Vreeburg, J. H. G. \& Boxall, J. B. 2007 Discolouration in potable water distribution systems: a review. Water Research 41 (3), 519-529.

Yang, F., Shi, B. Y., Gu, J. N., Wang, D. S. \& Yang, M. 2012 Morphological and physicochemical characteristics of iron corrosion scales formed under different water source histories in a drinking water distribution system. Water Research 46 (16), 5423-5433.

Yang, F., Shi, B. Y., Bai, Y. H., Sun, H. F., Lytle, D. A. \& Wang, D. S. 2014 Effect of sulfate on the transformation of corrosion scale composition and bacterial community in cast iron water distribution pipes. Water Research 59, 46-57.

First received 22 December 2016; accepted in revised form 6 June 2017. Available online 21 June 2017 